\section{BMJ Open Respiratory Research}

\title{
Validation of the STOP-Bang questionnaire as a screening tool for obstructive sleep apnoea in patients with cardiovascular risk factors: a systematic review and meta-analysis
}

\author{
Mark Hwang (D) , ${ }^{1}$ Kevin Zhang (D) , ${ }^{2}$ Mahesh Nagappa, ${ }^{3}$ Aparna Saripella, ${ }^{4}$ \\ Marina Englesakis, ${ }^{5}$ Frances Chung ${ }^{6}$
}

To cite: Hwang M, Zhang K, Nagappa M, et al. Validation of the STOP-Bang questionnaire as a screening tool for obstructive sleep apnoea in patients with cardiovascular risk factors: a systematic review and meta-analysis. BMJ Open Resp Res 2021;8:e00848. doi:10.1136/ bmjresp-2020-000848

- Additional material is published online only. To view, please visit the journal online (http://dx.doi.org/10. 1136/bmjresp-2020-000848)

Received 26 November 2020 Revised 22 January 2021 Accepted 26 January 2021
Check for updates

(C) Author(s) (or their employer(s)) 2021. Re-use permitted under CC BY-NC. No commercial re-use. See rights and permissions. Published by BMJ.

For numbered affiliations see end of article.

Correspondence to Dr Frances Chung; Frances.Chung@uhn.ca

\section{ABSTRACT}

Introduction Obstructive sleep apnoea (OSA) is highly prevalent in patients with cardiovascular risk factors and is associated with increased morbidity and mortality. This review presents the predictive parameters of the STOPBang questionnaire as a screening tool for OSA in this population.

Methods A search of databases was performed. The inclusion criteria were: (1) use of the STOP-Bang questionnaire to screen for OSA in adults ( $>18$ years) with cardiovascular risk factors; (2) polysomnography or home sleep apnoea testing performed as a reference standard; (3) OSA defined by either Apnoea-Hypopnoea Index (AHI) or Respiratory Disturbance Index; and (4) data on predictive parameters of the STOP-Bang questionnaire. A random-effects model was used to obtain pooled predictive parameters of the STOP-Bang questionnaire. Results The literature search resulted in 3888 articles, of which 9 papers met the inclusion criteria, involving 1894 patients. The average age of the included patients was $58 \pm 13$ years with body mass index (BMI) of $30 \pm 6 \mathrm{~kg} /$ $\mathrm{m}^{2}$, and $64 \%$ were male. The STOP-Bang questionnaire has a sensitivity of $89.1 \%, 90.7 \%$ and $93.9 \%$ to screen for all $(A H I \geq 5)$, moderate-to-severe $(A H I \geq 15)$ and severe (AHI $\geq 30)$ OSA, respectively. The specificity was $32.3 \%$, $22.5 \%$ and $18.3 \%$ and the area under the curve (AUC) was $0.86,0.65$ and 0.52 for all, moderate-to-severe and severe OSA, respectively.

Conclusion The STOP-Bang questionnaire is an effective tool to screen for OSA ( $\mathrm{AHI} \geq 5)$ with AUC of 0.86 in patients with cardiovascular risk factors.

\section{INTRODUCTION}

Obstructive sleep apnoea (OSA) is a common sleep-related breathing disorder, characterised by frequent apnoea and hypopnea episodes. ${ }^{1}$ The prevalence of OSA is higher among individuals with a high body mass index (BMI), increased age, narrow airway, sedentary lifestyle and persons of African,
Key messages

What is the key question?

- Is the STOP-Bang questionnaire a valid screening tool for obstructive sleep apnoea in patients with cardiovascular risk factors?

What is the bottom line?

- The STOP-Bang questionnaire is a valid screening tool with high sensitivity to detect obstructive sleep apnoea in patients with cardiovascular risk factors.

Why read on?

- This is the first study to review the current evidence on the use of the STOP-Bang questionnaire in patients with cardiovascular risk factors.

Native and Hispanic descent. ${ }^{12}$ However, it is estimated that up to $80 \%$ of patients with moderate-to-severe OSA remain undiagnosed, leading to poor quality of life, increased healthcare utilisation, and exacerbation of comorbid conditions. ${ }^{3-5}$ The gold standard for diagnosis of OSA is polysomnography (PSG), which is costly and requires overnight observation at a sleep laboratory. ${ }^{6}$ Given the high prevalence of OSA in the general population and limited resources for PSG, a number of clinical screening tools have been developed to help prioritise highrisk patients for diagnosis and treatment.

The STOP-Bang questionnaire is an easyto-administer OSA screening tool that has previously been validated in the sleep clinic and surgical populations. ${ }^{7-9}$ The questionnaire includes four binary (STOP: snoring, tiredness, observed apnoea and high blood pressure) and four demographic questions (BANG: BMI, age, neck circumference and gender).$^{7}$ Originally validated in the surgical population, the STOP-Bang questionnaire 
reported a sensitivity of $83.9 \%, 92.9 \%$ and $100 \%$ to screen for all OSA (Apnoea-Hypopnea Index (AHI) $\geq 5$ ), moderate-to-severe OSA (AHI $\geq 15$ ) and severe OSA (AHI $\geq 30)$, respectively. ${ }^{7}$ Worldwide, the STOP-Bang questionnaire has been used extensively in preoperative clinics, ${ }^{71011}$ various specialist clinics ${ }^{12}$ and in the general population. ${ }^{13}$

OSA has been associated with impaired endothelial function ${ }^{14}$ and various forms of cardiovascular disease, including hypertension, stroke, heart failure, atrial fibrillation and coronary artery disease. ${ }^{15}$ Given that patients with OSA and cardiovascular risk factors experience poor disease outcomes ${ }^{16}$ there is a need for an easy-to-administer OSA screening tool to identify highrisk individuals for diagnosis and treatment as well as to reduce morbidity and mortality in this population. The purpose of this systematic review and meta-analysis is to evaluate whether the STOP-Bang questionnaire is a valid screening tool for the screening of OSA in patients with cardiovascular risk factors.

\section{METHODS}

\section{Study design and registration}

The protocol of this study was registered in the International Prospective Register of Systematic Reviews (PROSPERO; registration CRD42020197390). We followed the Preferred Reporting Items for Systematic Reviews and Meta-analyses (PRISMA) guideline. ${ }^{17}$

\section{Literature search strategy}

We searched for articles published in the following electronic databases: MEDLINE (Ovid), MEDLINE In-Process/ePubs, Embase, EmCare Nursing, Cochrane Central Register of Controlled Trials, Cochrane Database of Systematic Reviews, PsycINFO, Web of Science (Clarivate), Scopus (Elsevier), CINAHL with full text (EBSCOhost) and Journals@Ovid using search strategy that was designed for each database by an information specialist (ME). All queries started from 2008 when the STOP-Bang questionnaire was first published and our search ended in March 2020. Only English abstracts were included in the search. No other limits were applied. The search strategy included the following free-text terms: 'stop-bang', 'stopbang'. A manual citation search of Google Scholar and PubMed was conducted to identify missed articles. Continued literature surveillance was done through August 2020.

\section{Study selection and data management}

Two reviewers (MH, AS) independently conducted title and abstract screening using Rayyan. MH and KZ conducted full-text evaluation, data extraction and risk of bias assessment. Full-text articles were selected according to the following inclusion criteria: (1) the study assessed the STOP-Bang questionnaire as a screening tool for OSA in adults with cardiovascular risk factors; (2) PSG or home sleep apnoea testing was performed to confirm OSA diagnosis; (3) OSA was defined by an AHI or Respiratory Disturbance Index cut-offs $\geq 5, \geq 15$ and $\geq 30$ events per hour; and (4) data on predictive parameters of the STOP-Bang questionnaire were provided. We defined cardiovascular risk factors as diabetes mellitus, hypertension, hyperlipidaemia, obesity, heart disease and cerebrovascular disease. In addition, disorders for which cardiovascular risk factors are major risk factors or part of the disease process were also included. All study subjects had at least one of the above risk factors to be included. Data from included studies were extracted using standardised data collection forms. Any disagreements between the reviewers were resolved by a third reviewer $(\mathrm{MN})$. The data extraction process was managed using Microsoft Excel 2016.

\section{Assessment of methodological quality}

The internal and external validity of the included studies were assessed by the reviewers (MH, KZ) independently using the criteria coded according to the Cochrane Screening and Diagnostic Tests Methods Group. ${ }^{18}$ The reviewers met to discuss the results of their appraisal and any outstanding disagreements were resolved by a third reviewer $(\mathrm{MN})$. The internal validity included the following criteria: valid reference standard, definition of disease, blind execution of index and reference tests, interpretation of index test independent of clinical information and study design. The external validity included the following criteria: spectrum of disease, clinical setting, previous screening or referral filter, demographic information, explicit cut-off of index test, percentage of missing participants, missing data management and participant selection for reference test. In addition, the reviewers graded the quality of each included study using the QUADAS tool with a score range from 0 to $14 .{ }^{19}$

\section{Statistical analysis}

For each of the included studies, the paired and unpaired predictive parameters were calculated using $2 \times 2$ contingency tables. A bivariate random-effects model was used to obtain pooled predictive parameters (sensitivity, specificity, positive predictive value (PPV) and negative predictive value (NPV), diagnostic OR and area under the curve (AUC) ) to assess the validity of the STOP-Bang questionnaire for different AHI cut-offs: AHI $\geq 5$, AHI $\geq 15$ and AHI $\geq 30$ events per hour. The meta-analysis was carried out with Review Manager V.5.4 and MetaDisc V.1.4.

\section{RESULTS}

The literature search resulted in 3888 articles (figure 1). After screening titles and abstracts, 2279 studies were excluded because they did not meet the predetermined inclusion criteria. Of the remaining 17 studies, 8 full-text articles were excluded ${ }^{20-27}$; the reasons for exclusion are listed in online supplemental table S1. Nine studies met 


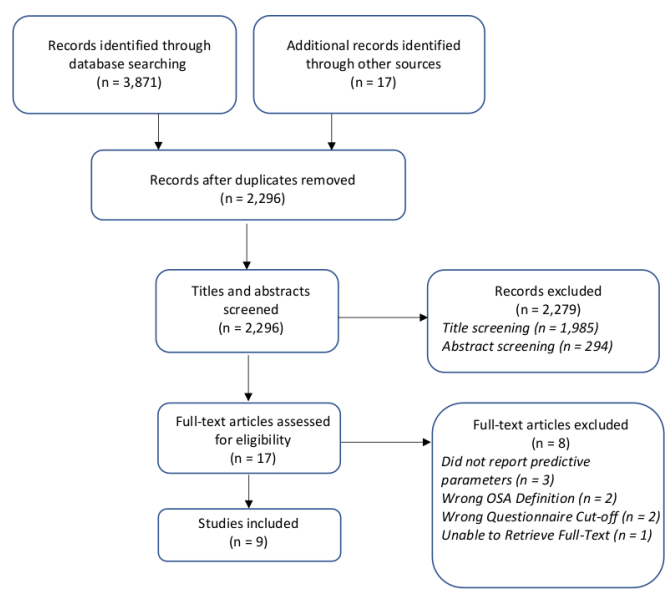

Figure 1 PRISMA study flow. AHI, apnoea-hypopnea index; OSA, obstructive sleep apnoea; PRISMA, Preferred Reporting Items for Systematic Reviews and Metaanalyses.

the inclusion criteria and were included in the review. ${ }^{28-36}$ The included studies encompassed 1894 patients and were conducted in six different countries: Australia, ${ }^{31}$ Canada, ${ }^{30}$ China, ${ }^{33-35}$ Czech Republic, ${ }^{29}$ Germany, ${ }^{32}$ and Italy. ${ }^{28}$

The demographics of the included studies are summarised in table 1 . The average age of patients with cardiovascular risk factors was $58 \pm 13$ years with BMI of $30 \pm 6 \mathrm{~kg} / \mathrm{m}^{2}$, and $64 \%$ were male. The characteristics of the included studies are summarised in table 2. All included studies were of prospective design, except one study which was retrospective. ${ }^{35}$ Six studies ${ }^{28-30} 333536$ used
AHI cut-off of $\geq 5$, one ${ }^{31}$ used Respiratory Event Index $\geq 5$ and two ${ }^{32}{ }^{34}$ used AHI $\geq 15$ to define OSA. The prevalence of OSA ranged from $38 \%$ to $96 \%$. The cardiovascular risk factors explored in the studies included diabetes mellitus $^{2931-33}(\mathrm{n}=4)$, stroke ${ }^{323435}(\mathrm{n}=3)$, heart disease $\mathrm{s}^{30-32}$ $(n=3)$, hypertension $^{31}{ }^{32}(\mathrm{n}=2)$, retinal vein occlusion ${ }^{36}$ $(n=1)$ and non-alcoholic fatty liver disease ${ }^{28}(n=1)$. Retinal vein occlusion was included for its close association with cardiovascular risk factors ${ }^{3738}$ which contribute directly to the pathogenesis. ${ }^{39} 40$ Similarly, non-alcoholic fatty liver disease was included as it is highly associated with cardiovascular risk factors ${ }^{41-43}$ in a bidirectional manner. ${ }^{44}$ Among the population with cardiovascular risk factors, $\operatorname{six}^{28-313335}(\mathrm{n}=1680)$, eight ${ }^{29-36}(\mathrm{n}=1844)$ and five studies $^{29-31} 3335$ ( $\mathrm{n}=1630$ ) were included for meta-analysis at the AHI cut-offs of $\geq 5, \geq 15, \geq 30$, respectively (figures 2 and 3, online supplemental figure S2).

\section{Methodological quality of the included studies}

The QUADAS scores of included studies ranged from 11 to 14 , indicating high quality studies with low risk of bias (table 1). All included studies used laboratory PSG or Home Sleep Apnoea Testing (HSAT) as a reference test to verify the accuracy of the STOP-Bang questionnaire, confirming internal validity (table 2). For validation purposes, four studies ${ }^{33-36}$ (44\%) used PSG, while five e $^{28-32}$ $(56 \%)$ used HSAT. Although PSG is the gold standard diagnostic modality, no significant differences were noted between studies that used PSG and HSAT with regard to OSA prevalence (table 2) and predictive parameters of the STOP-Bang questionnaire (figure 2). Blinding to the

\begin{tabular}{|c|c|c|c|c|c|c|c|c|}
\hline $\begin{array}{l}\text { Study ID } \\
\text { (country) }\end{array}$ & $\begin{array}{l}\text { Age } \\
\text { (year) }\end{array}$ & $\begin{array}{l}\text { Gender } \\
(\%) \text { male }\end{array}$ & $\begin{array}{l}\mathrm{BMI} \\
\left(\mathrm{kg} / \mathrm{m}^{2}\right)\end{array}$ & $\begin{array}{l}\text { Neck circumference } \\
\text { (cm) }\end{array}$ & $\begin{array}{l}\text { STOP-Bang } \\
\text { score }\end{array}$ & AHI (mean) & $\begin{array}{l}\text { Minimum } \\
\mathrm{SpO}_{2}(\%)\end{array}$ & $\begin{array}{l}\text { QUADAS } \\
\text { score }\end{array}$ \\
\hline $\begin{array}{l}\text { Petta et al } \\
\text { Italy }\end{array}$ & $53 \pm 11$ & 58 & $32 \pm 5$ & NR & NR & $11.0 \pm 13.1$ & NR & 12 \\
\hline $\begin{array}{l}\text { Westlake et al } \\
\text { Czech Republic }\end{array}$ & $64 \pm 9$ & 59 & $31 \pm 6$ & $42 \pm 4$ & NR & $13.6 \pm 14.7$ & NR & 13 \\
\hline $\begin{array}{l}\text { Abumuamar et al } \\
\text { Canada }\end{array}$ & $63 \pm 13$ & 64 & $29 \pm 6$ & NR & $4 \pm 1$ & $20.0 \pm 17.0$ & NR & 13 \\
\hline $\begin{array}{l}\text { Kee et al } \\
\text { Australia }^{31}\end{array}$ & $59 \pm 12$ & 63 & $33 \pm 6$ & $41 \pm 4$ & NR & REl: $15.0 \pm 14.0$ & NR & 14 \\
\hline $\begin{array}{l}\text { Reuter et al } \\
\text { Germany }{ }^{32}\end{array}$ & $58 \pm 15$ & 58 & $30 \pm 6$ & $41 \pm 4$ & NR & $15.0 \pm 15.0$ & $81 \pm 9$ & 11 \\
\hline $\begin{array}{l}\text { Teng et al } \\
\text { China }^{33}\end{array}$ & $49 \pm 11$ & 63 & $28 \pm 4$ & $37 \pm 5$ & $3.7 \pm 2$ & $22.1 \pm 9.5$ & NR & 14 \\
\hline $\begin{array}{l}\text { Zeng et al } \\
\text { China }^{34}\end{array}$ & $63 \pm 13$ & 67 & $25 \pm 3$ & $38 \pm 3$ & NR & NR & $82 \pm 8$ & 11 \\
\hline $\begin{array}{l}\text { Chen et al } \\
\text { China }^{35}\end{array}$ & $54 \pm 13$ & 80 & $27 \pm 4$ & $39 \pm 4$ & $4.1 \pm 1$ & $25.5 \pm 24.9$ & $77 \pm 13$ & 12 \\
\hline $\begin{array}{l}\text { Felfeli et al } \\
\text { Canada }^{36}\end{array}$ & $70 \pm 12$ & 41 & $28 \pm 5$ & NR & NR & $31.3 \pm 20.8$ & $83 \pm 7$ & 14 \\
\hline
\end{tabular}

Data are presented as mean $\pm S D$, where appropriate.

AHI, Apnoea-Hypopnea index; Bang, BMI, age, neck circumference and gender; BMI, body mass index; NR, not reported; REI,

Respiratory Event Index; $\mathrm{SPO}_{2}$, haemoglobin oxygen saturation; STOP, snoring, tiredness, observed apnoea and high blood pressure. 


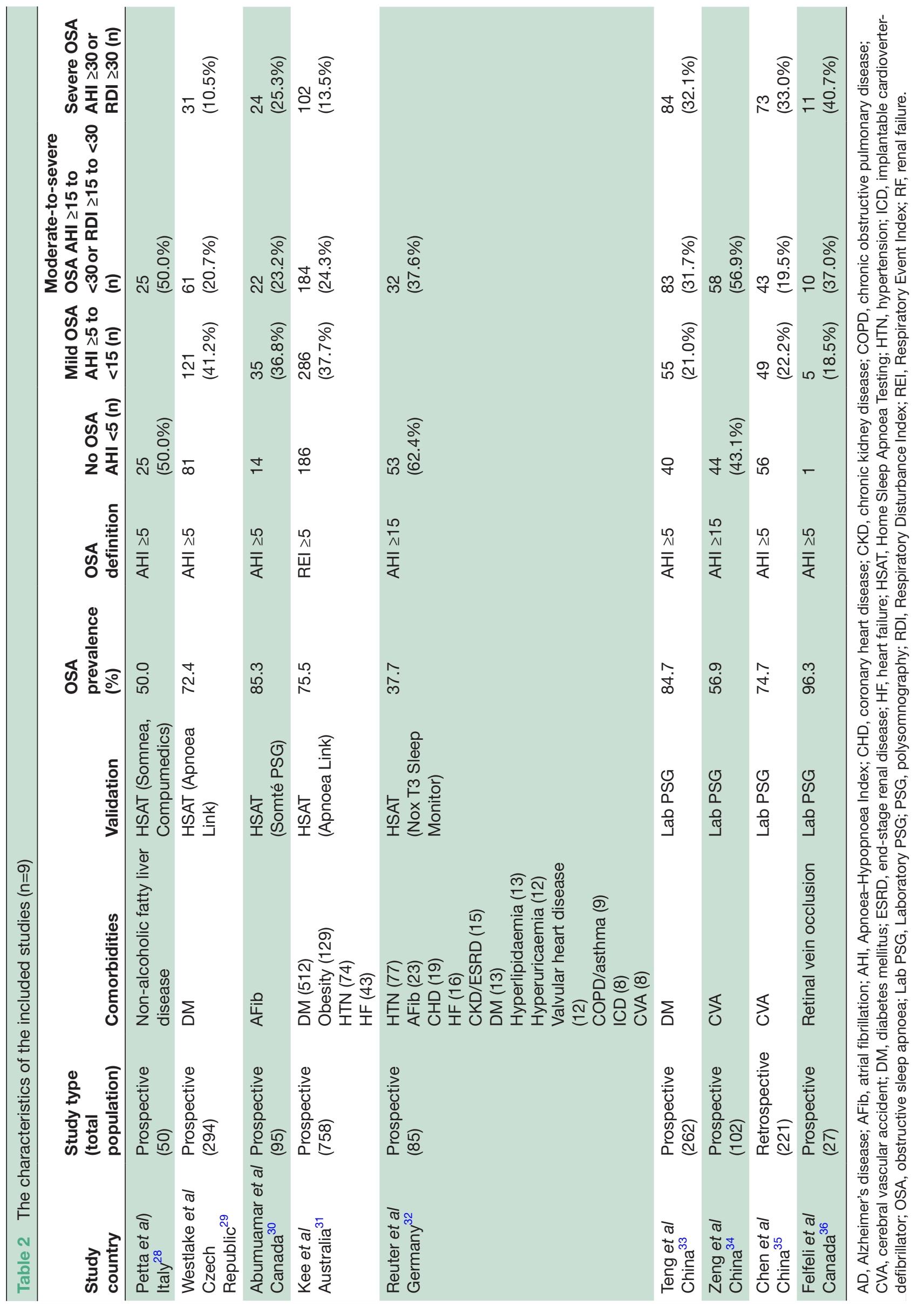

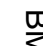




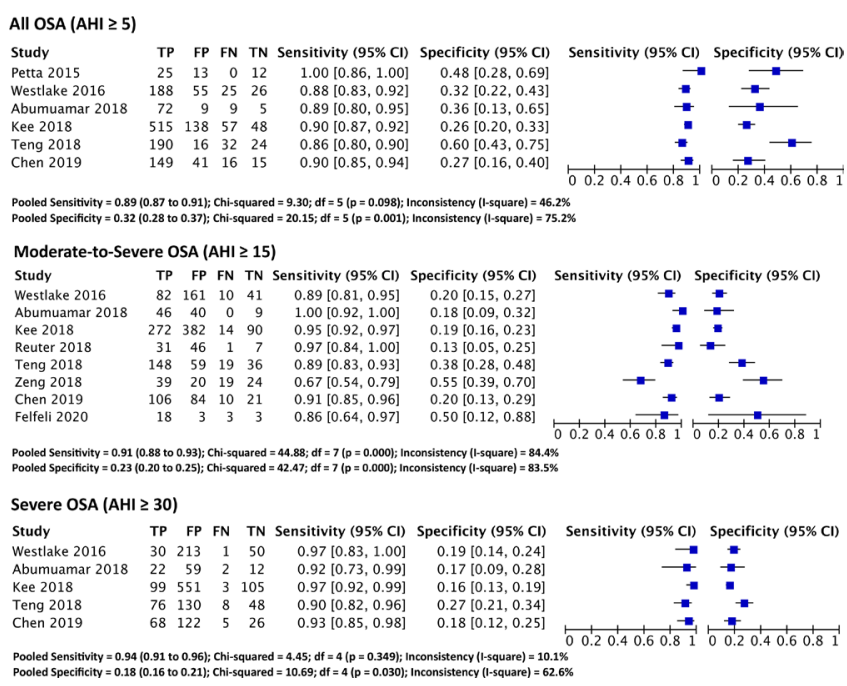

Figure 2 Forest plots for pooled sensitivity and specificity of STOP-Bang questionnaire for various OSA severities in patients with cardiovascular risk factors. Values are presented as means with $95 \% \mathrm{Cl}$ in parentheses. AHI, Apnoea-Hypopnea index; Bang, BMI, age, neck circumference and gender; OSA, obstructive sleep apnoea; STOP, snoring, tiredness, observed apnoea and high blood pressure.

index and reference tests was done in four studies 30313336 (44\%), while the results of the STOP-Bang questionnaire were interpreted independent of clinical information in three studies ${ }^{303133}$ (33\%, online supplemental table S3). The appraisal of included studies based on criteria for external validity are summarised in online supplemental table S4. Eight studies ${ }^{28-3133-36}(89 \%)$ clearly described the inclusion and exclusion criteria with the exception of one study. ${ }^{32}$ All nine studies provided enough information to identify the study setting, in addition to demographic data including age, gender, and BMI. All studies did not pre-screen for OSA prior to the application of the STOP-Bang questionnaire and all participants were invited or randomly selected for PSG or HSAT, suggesting an unbiased selection for the reference test.

\section{Predictive parameters of the STOP-Bang questionnaire in patients with cardiovascular risk factors}

The pooled predictive parameters of STOP-Bang score $\geq 3$ to screen for OSA in patients with cardiovascular risk factors are presented in table 3 , figures 2 and 3 and online supplemental figure S2. The prevalence of all OSA (AHI $\geq 5$ ), moderate-to-severe OSA (AHI $\geq 15)$ and severe OSA (AHI $\geq 30$ ) was $76 \%, 44 \%$ and $19 \%$, respectively. The STOP-Bang questionnaire has a high pooled sensitivity of $89.1 \%$ (95\% CI: $87.3 \%$ to $90.8 \% ; \mathrm{I}^{2}=46.2 \%$ ), $90.7 \%$ (95\% CI: $88.5 \%$ to $\left.92.6 \% ; \mathrm{I}^{2}=84.4 \%\right)$, and $93.9 \%$ (95\% CI: $90.1 \%$ to $96.3 \%$; $\mathrm{I}^{2}=10.1 \%$ ) to screen for all $(\mathrm{AHI} \geq 5)$, moderate-to-severe (AHI $\geq 15)$ and severe (AHI $\geq 30$ ) OSA, respectively. We explored the heterogeneity contribution from these studies and found that in AHI $\geq 5$, a study by Petta $e t a l^{28}$ contributed to the maximum
All OSA (AHI $\geq 5)$

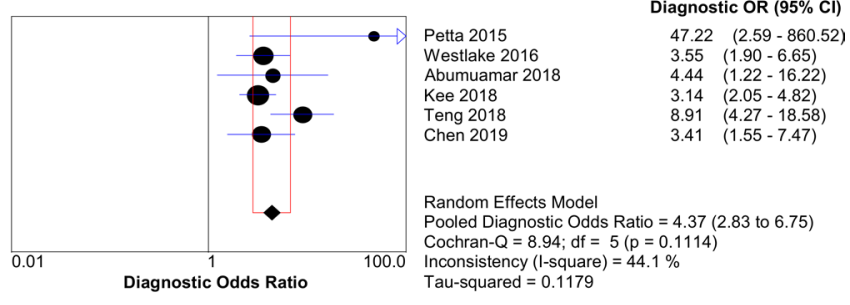

Moderate-to-Severe OSA (AHI $\geq 15)$

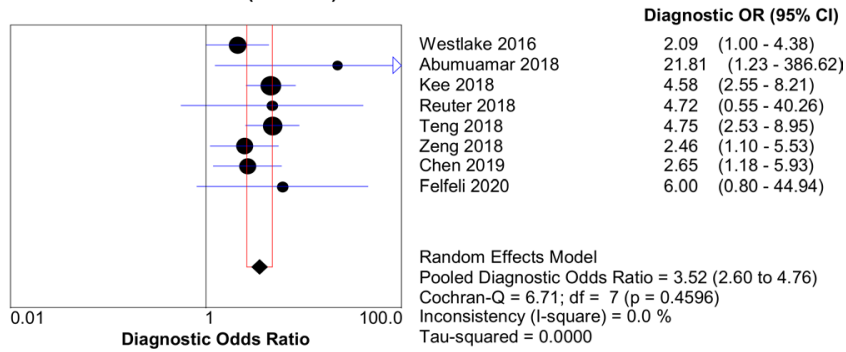

Severe OSA $(A H I \geq 30)$

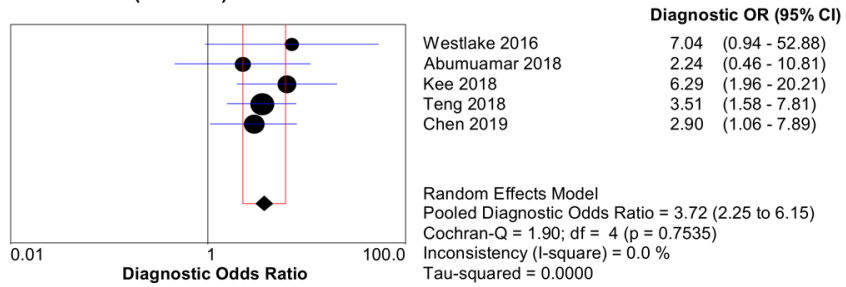

Figure 3 Forest plot for pooled diagnostic OR for various OSA severities for patients with cardiovascular risk factors. Values are presented as means with $95 \%$ $\mathrm{Cl}$ in parentheses. AHI, Apnoea-Hypopnea index; OSA, obstructive sleep apnoea.

heterogeneity (online supplemental figure S5). Our sensitivity analysis by removing Petta $e t a t^{28}$ found that heterogeneity decreased from $46.2 \%$ to $0 \%$ (online supplemental figure S5). Similar analysis was done for AHI $\geq 15$, where we found that heterogeneity decreased from $84.4 \%$ to $65.3 \%$ after removing the Zeng et al. ${ }^{34}$ The pooled specificities were relatively low at $32.3 \%(95 \% \mathrm{CI}$ : $27.8 \%$ to $37.2 \%$; $\mathrm{I}^{2}=75.2 \%$ ), $22.5 \%$ (95\% CI: $20.0 \%$ to $25.2 \% ; \mathrm{I}^{2}=83.5 \%$ ) and $18.3 \%$ (95\% CI: $16.3 \%$ to $20.5 \%$; $\mathrm{I}^{2}=62.6 \%$ ) for all, moderate-to-severe and severe OSA, respectively.

The pooled positive predictive value (PPV) was highest at $80.7 \%$ (95\% CI: $78.5 \%$ to $82.7 \%$ ) to differentiate all OSA from non-OSA, with corresponding PPVs of $48.3 \%$ (95\% CI: $45.8 \%$ to $50.8 \%$ ) and $21.5 \%$ (95\% CI: $19.4 \%$ to $23.8 \%$ ) for moderate-to-severe and severe OSA, respectively (table 3 ). With a negative predictive value (NPV) of $92.7 \%$ (95\% CI: $88.6 \%$ to $95.4 \%$ ), the STOP-Bang questionnaire is most effective in ruling-out severe OSA. The corresponding NPVs are $48.3 \%$ (95\% CI: $42.2 \%$ to $54.5 \%$ ) and $75.2 \%$ (95\% CI: $70.0 \%$ to $79.9 \%$ ) for all OSA and moderate-to-severe OSA, respectively. The diagnostic odds ratio was 4.37 (2.83-6.75), 3.52 (2.60$4.77)$ and 3.72 (2.25-6.15) for all, moderate-to-severe and severe OSA, respectively. The AUC was $0.86,0.65$ 


\begin{tabular}{|c|c|c|c|}
\hline $\begin{array}{l}\text { Predictive parameters } \\
(95 \% \mathrm{Cl})\end{array}$ & All OSA AHI $\geq 5$ & Moderate-to-severe OSA AHI $\geq 15$ & Severe OSA AHI $\geq 30$ \\
\hline & (six studies, $n=1680$ ) & (eight studies, $n=1844$ ) & (five studies, $n=1630$ ) \\
\hline Prevalence & 76.1 (73.9-78.1) & $44.4(42.1-46.7)$ & $19.3(17.4-21.3)$ \\
\hline Sensitivity & $89.1(87.3-90.8)$ & $90.7(88.5-92.6)$ & $93.9(90.1-96.3)$ \\
\hline Specificity & $32.3(27.8-37.2)$ & $22.5(20.0-25.2)$ & $18.3(16.3-20.5)$ \\
\hline PPV & $80.7(78.5-82.7)$ & $48.3(45.8-50.8)$ & $21.5(19.4-23.8)$ \\
\hline NPV & $48.3(42.2-54.5)$ & $75.2(70.0-79.9)$ & $92.7(88.6-95.4)$ \\
\hline Diagnostic OR & $4.37(2.83-6.75)$ & $3.52(2.60-4.77)$ & $3.72(2.25-6.15)$ \\
\hline AUC & $\begin{array}{l}0.86 \\
S E=0.054\end{array}$ & $\begin{array}{l}0.65 \\
S E=0.064\end{array}$ & $\begin{array}{l}0.52 \\
S E=0.24\end{array}$ \\
\hline
\end{tabular}

Data are presented as means with $95 \% \mathrm{Cl}$ in parentheses, where appropriate.

AHI, Apnoea-Hypopnea index; AUC, area under the ROC curve; BANG, BMI, age, neck circumference and gender; NPV, negative predictive value; OSA, obstructive sleep apnoea; PPV, positive predictive value; STOP, snoring, tiredness, observed apnoea and high blood pressure.

and 0.52 for all, moderate-to-severe and severe OSA, respectively.

\section{Predictive parameters of the various STOP-Bang scores}

The predictive parameters of different STOP-Bang score cut-offs for all OSA ( $\mathrm{n}=3045)$, moderate-to-severe OSA $(n=3209)$ and severe OSA $(n=2995)$ among patients with cardiovascular risk factors are summarised in online supplemental table S6. As the STOP-Bang score cut-off increased from 3 to 6 , the sensitivity decreased from $89 \%$ to $14 \%$ for all OSA, $91 \%$ to $15 \%$ for moderate-to-severe OSA and $94 \%$ to $21 \%$ for severe OSA, respectively. For all OSA, moderate-to-severe OSA and severe OSA, there was an increase in specificity from $32 \%$ to $100 \%, 23 \%$ to $93 \%$ and $18 \%$ to $93 \%$, respectively, when the cut-off increased from 3 to 6 . The PPVs were high for all OSA at $81 \%$ for STOP-Bang cut-offs of $\geq 3$ and highest at $100 \%$ for $\geq 6$, respectively. The NPVs were highest for severe OSA at $93 \%$ for STOP-Bang cut-offs of $\geq 3$ and high at $73 \%$ for cut-offs of $\geq 6$, respectively.

\section{DISCUSSION}

To date, this is the first meta-analysis of the validity of the STOP-Bang questionnaire in patients with cardiovascular risk factors. We found that the STOP-Bang questionnaire with a cut-off score $\geq 3$ has excellent AUC at 0.86 in detecting OSA in patients with cardiovascular risk factors. Our findings are similar to those reported by previous reviews that validated the STOP-Bang questionnaire in the surgical and sleep clinic populations. ${ }^{78}$

The high false positive rate, and hence the low specificity, especially in detecting moderate-to-severe OSA, could be explained by the fact that some cardiovascular risk factor symptoms overlap with those of OSA. Heart failure and history of stroke, both of which showed high prevalence in our review, have previously been found to be accompanied by daytime fatigue and sleepiness. ${ }^{45-47}$
These symptoms could have increased the STOP-Bang score and thus resulted in false positives.

The sensitivity and specificity are important parameters for clinicians to consider when selecting a screening tool. The two are inversely proportional, meaning that high sensitivity usually comes at a cost to specificity and vice versa. In conditions for which the diagnostic test is costly, invasive or poses a risk to the patient, the screening tool should be highly specific, minimising false positives and the need to undergo the diagnostic test. In the context of OSA, the sensitivity of a screening tool is more important, as the diagnostic test (PSG or HSAT) is not associated with risk to the patient and is becoming increasingly affordable. ${ }^{48} 49$ In addition, missed OSA cases can incur substantial healthcare strain $^{50-52}$ and indirect costs due to lost productivity and decreased quality-of-life, ${ }^{53-56}$ further substantiating the utility of a highly sensitive screening tool even at the cost of low specificity. The findings of our meta-analysis show that the STOP-Bang questionnaire fulfils this need as a valid screening tool for enhancing early detection of OSA in patients with cardiovascular risk factors.

\section{Use of the STOP-Bang questionnaire in patients with cardiovascular risk factors}

OSA is closely associated with various forms of cardiovascular disease, ${ }^{15}{ }^{57-60}$ including hypertension, stroke, heart failure, atrial fibrillation, coronary artery disease and cerebrovascular disease, with increased risk of adverse outcomes. ${ }^{16}{ }^{61}$ Given the high prevalence ${ }^{62}$ of undiagnosed and untreated OSA among patients with cardiovascular disease, a valid, accessible and easy-to-administer screening tool is crucial. The STOP-Bang questionnaire can be quickly administered as it involves a few simple questions and has been found to have a high response rate. ${ }^{763}$ The NPV of STOP-Bang score 0-2 allows us to safely exclude moderate-to-severe OSA in patients with cardiovascular risk factors. These characteristics, combined with the high sensitivity, make the STOPBang questionnaire a useful tool in identifying patients with 
cardiovascular risk factors who may be at high-risk for undiagnosed OSA to receive expedited diagnosis and treatment.

Although the current guidelines recommend continuous positive airway pressure (CPAP) treatment as initial therapy for patients with OSA, ${ }^{64}$ there is insufficient evidence on the efficacy of CPAP therapy in reducing all-cause or cardiovascular mortality and morbidity in patients with OSA and cardiovascular disease. ${ }^{656}$ One review found that CPAP therapy significantly improved sleep outcomes (AHI and Epworth sleepiness scale) and mental-component quality of life scores. ${ }^{65}$ As such, the current evidence is limited to demonstrating the efficacy of CPAP therapy to symptomatic improvements of OSA in patients with cardiovascular risk factors. Further research is needed to fully establish the impact of CPAP therapy and ultimately the effectiveness of screening tools such as the STOP-Bang questionnaire on improving clinical outcomes in cardiovascular patients with OSA.

\section{Limitations}

Our systematic review and meta-analysis has some limitations. Although all studies enroled patients without prescreening before the questionnaire was administered, the high prevalence could indicate some degree of selection bias. Second, there is significant between-study heterogeneity in sensitivity and specificity. One contributing factor to the observed variation could be the different validation devices HSAT or PSG among studies. Another factor for the variance may be the different geographic locations and clinical heterogeneity regarding the type of cardiovascular risk factor. Nevertheless, we used a random effects model, which is appropriate for a heterogenous sample. Third, the small number of included studies precluded the use of meta-regression analysis to establish the impact of potential confounders. Lastly, we only included studies with abstracts in the English language. Despite these limitations, our systematic review and meta-analysis provide a summary of the current literature on the STOP-Bang questionnaire and recommends its use as a screening tool in patients with OSA and cardiovascular risk factors.

\section{CONCLUSIONS}

In summary, this meta-analysis shows that the STOP-Bang questionnaire is a valid screening tool for detecting OSA in patients with cardiovascular risk factors. The high sensitivity and PPV of the STOP-Bang questionnaire enables risk stratification and early detection, facilitating the diagnosis and treatment of OSA.

\section{Author affiliations}

${ }^{1}$ Faculty of Medicine, Medicine, The University of British Columbia, Vancouver, British Columbia, Canada

${ }^{2}$ Faculty of Medicine, Medicine, University of Toronto, Toronto, Ontario, Canada

${ }^{3}$ Department of Anaesthesia \& Perioperative Medicine, London Health Sciences Centre, London, Ontario, Canada
${ }^{4}$ Department of Anaesthesia and Pain Medicine, University Health Network, Toronto, Ontario, Canada

${ }^{5}$ Library and Information Services, University Health Network, Toronto, Ontario, Canada

${ }^{6}$ Department of Anaesthesia and Pain Medicine, Toronto Western Hospital, Toronto, Ontario, Canada

Contributors Study concept and design was performed by MH, MN and FC. Literature search was done by ME. Acquisition, analysis and interpretation of data were done by all the authors. Statistical analysis was performed by MH, KZ, MN and AS. Drafting of the manuscript was done by MH, KZ, MN and FC. All authors performed critical revision of the manuscript for important intellectual content. FC guarantees the integrity of the work.

Funding The authors have not declared a specific grant for this research from any funding agency in the public, commercial or not-for-profit sectors.

Competing interests None declared.

Patient consent for publication Not required.

Provenance and peer review Not commissioned; externally peer reviewed.

Data availability statement All data relevant to the study are included in the article or uploaded as supplementary information.

Author note The institution where the work was performed: University Health Network, University of Toronto, MCL 2-405, 399 Bathurst Street, Toronto, ON, Canada, M5T2S8.

Supplemental material This content has been supplied by the author(s). It has not been vetted by BMJ Publishing Group Limited (BMJ) and may not have been peer-reviewed. Any opinions or recommendations discussed are solely those of the author(s) and are not endorsed by BMJ. BMJ disclaims all liability and responsibility arising from any reliance placed on the content. Where the content includes any translated material, BMJ does not warrant the accuracy and reliability of the translations (including but not limited to local regulations, clinical guidelines, terminology, drug names and drug dosages), and is not responsible for any error and/or omissions arising from translation and adaptation or otherwise.

Open access This is an open access article distributed in accordance with the Creative Commons Attribution Non Commercial (CC BY-NC 4.0) license, which permits others to distribute, remix, adapt, build upon this work non-commercially, and license their derivative works on different terms, provided the original work is properly cited, appropriate credit is given, any changes made indicated, and the use is non-commercial. See: http://creativecommons.org/licenses/by-nc/4.0/.

ORCID iDs

Mark Hwang http://orcid.org/0000-0002-4043-7085

Kevin Zhang http://orcid.org/0000-0003-1183-5743

\section{REFERENCES}

1 Benjafield AV, Ayas NT, Eastwood PR, et al. Estimation of the global prevalence and burden of obstructive sleep apnoea: a literaturebased analysis. Lancet Respir Med 2019;7:687-98.

2 Dudley KA, Patel SR. Disparities and genetic risk factors in obstructive sleep apnea. Sleep Med 2016;18:96-102.

3 Young T, Skatrud J, Peppard PE. Risk factors for obstructive sleep apnea in adults. JAMA 2004;291:2013-6.

4 Kapur V, Strohl KP, Redline S, et al. Underdiagnosis of sleep apnea syndrome in U.S. communities. Sleep Breath 2002;6:49-54.

5 Young T, Evans L, Finn L, et al. Estimation of the clinically diagnosed proportion of sleep apnea syndrome in middle-aged men and women. Sleep 1997;20:705-6.

6 McNicholas WT. Diagnosis of obstructive sleep apnea in adults. Proc Am Thorac Soc 2008;5:154-60.

7 Chung F, Yegneswaran B, Liao P, et al. Stop questionnaire: a too to screen patients for obstructive sleep apnea. Anesthesiology 2008;108:812-21.

8 Nagappa M, Liao P, Wong J, et al. Validation of the Stop-Bang questionnaire as a screening tool for obstructive sleep apnea among different populations: a systematic review and meta-analysis. PLoS One 2015;10:e0143697.

9 Waseem R, Chan MTV, Wang CY, et al. Diagnostic performance of the Stop-Bang questionnaire as a screening tool for obstructive sleep apnea in different ethnic groups. J Clin Sleep Med 2020.

10 Nunes FS, Danzi-Soares NJ, Genta PR, et al. Critical evaluation of screening questionnaires for obstructive sleep apnea in patients undergoing coronary artery bypass grafting and abdominal surgery. Sleep Breath 2015;19:115-22. 
11 Chung F, Subramanyam R, Liao P, et al. High Stop-Bang score indicates a high probability of obstructive sleep apnoea. $\mathrm{Br} J$ Anaesth 2012;108:768-75.

12 Nicholl DDM, Ahmed SB, Loewen AHS, et al. Diagnostic value of screening instruments for identifying obstructive sleep apnea in kidney failure. J Clin Sleep Med 2013;9:31-8.

13 Silva GE, Vana KD, Goodwin JL, et al. Identification of patients with sleep disordered breathing: comparing the four-variable screening tool, stop, Stop-Bang, and Epworth sleepiness scales. J Clin Sleep Med 2011;7:467-72.

14 Budhiraja R, Parthasarathy S, Quan SF. Endothelial dysfunction in obstructive sleep apnea. J Clin Sleep Med 2007;3:409-15.

15 Shahar E, Whitney CW, Redline S, et al. Sleep-disordered breathing and cardiovascular disease: cross-sectional results of the sleep heart health study. Am J Respir Crit Care Med 2001;163:19-25.

16 Tietjens JR, Claman D, Kezirian EJ, et al. Obstructive sleep apnea in cardiovascular disease: a review of the literature and proposed multidisciplinary clinical management strategy. J Am Heart Assoc 2019;8:e010440.

17 Liberati A, Altman DG, Tetzlaff J, et al. The PRISMA statement for reporting systematic reviews and meta-analyses of studies that evaluate healthcare interventions: explanation and elaboration. $B M J$ 2009;339:b2700

18 Cochrane Screening and Diagnostic Tests Methods Group. Available: http://srdta.cochrane.org

19 Whiting P, Rutjes AWS, Reitsma JB, et al. The development of QUADAS: a tool for the quality assessment of studies of diagnostic accuracy included in systematic reviews. BMC Med Res Methodol 2003;3:25.

20 Teng Y, Xiong Y, Wang N. [The applications of the STOP-Bang questionnaire in screening obstructive sleep apnea in patients with metabolic syndrome]. Zhonghua Jie He He Hu Xi Za Zhi 2015;38:461-6.

21 Katzan IL, Thompson NR, Uchino K, et al. A screening tool for obstructive sleep apnea in cerebrovascular patients. Sleep Med 2016;21:70-6.

22 Pavarangkul T, Jungtrakul T, Chaobangprom P, et al. The Stop-Bang questionnaire as a screening tool for obstructive sleep ApneaInduced hypertension in Asian population. Neurol Int 2016;8:6104.

23 Donovan LM, Rueschman M, Weng J, et al. The effectiveness of an obstructive sleep apnea screening and treatment program in patients with type 2 diabetes. Diabetes Res Clin Pract 2017;134:145-52.

24 Sico JJ, Yaggi HK, Ofner S, et al. Development, validation, and assessment of an ischemic stroke or transient ischemic AttackSpecific prediction tool for obstructive sleep apnea. J Stroke Cerebrovasc Dis 2017;26:1745-54.

25 Vicente-Herrero MT, Capdevila García L, Bellido Cambrón MDC, et al. Cardiovascular risk and obesity in sleep apnea syndrome assessed with the Stop-Bang questionnaire. Endocrinol Diabetes Nutr 2017;64:544-51.

26 Vicente-Herrero MT, Capdevila-García L, Bellido-Cambrón MC. Obstructive sleep apnea assessed with Epworth and Stop-Bang questionnaires and its relationship with metabolic syndrome. Med Int Mex 2018;34:373-80.

27 Zhang L, Zeng T, Gui Y, et al. Application of neck circumference in Four-Variable screening tool for early prediction of obstructive sleep apnea in acute ischemic stroke patients. J Stroke Cerebrovasc Dis 2019;28:2517-24

28 Petta S, Marrone O, Torres D, et al. Obstructive sleep apnea is associated with liver damage and atherosclerosis in patients with non-alcoholic fatty liver disease. PLoS One 2015;10:e0142210.

29 Westlake K, Plihalova A, Pretl M, et al. Screening for obstructive sleep apnea syndrome in patients with type 2 diabetes mellitus: a prospective study on sensitivity of Berlin and Stop-Bang questionnaires. Sleep Med 2016;26:71-6.

30 Abumuamar AM, Dorian P, Newman D, et al. The Stop-Bang questionnaire shows an insufficient specificity for detecting obstructive sleep apnea in patients with atrial fibrillation. J Sleep Res 2018;27:e12702.

31 Kee K, Dixon J, Shaw J, et al. Comparison of commonly used questionnaires to identify obstructive sleep apnea in a high-risk population. J Clin Sleep Med 2018;14:2057-64.

32 Reuter H, Herkenrath S, Treml M, et al. Sleep-disordered breathing in patients with cardiovascular diseases cannot be detected by ESS, STOP-BANG, and Berlin questionnaires. Clin Res Cardiol 2018;107:1071-8.

33 Teng Y, Wang S, Wang N, et al. Stop-Bang questionnaire screening for obstructive sleep apnea among Chinese patients with type 2 diabetes mellitus. Arch Med Sci 2018;14:971-8.

34 Zeng T, Zhang L, Yang Y. [Screening efficiencies of obstructive sleep apnea screening scales in patients with acute ischemic stroke].
Zhejiang Xue Xue Bao Yi Xue BanJournal Zhejiang Univ Med Sci 2018;47:174-80.

35 Chen R, Liu W, Cheng J, et al. The No-apnea score vs. the other five questionnaires in screening for obstructive sleep apneahypopnea syndrome in patients with cerebral infarction. $J$ Thorac Dis 2019:11:4179-87.

36 Felfeli T, Alon R, Al Adel F, et al. Screening for obstructive sleep apnea amongst patients with retinal vein occlusion. Can $J$ Ophthalmol 2020;55:310-6.

37 Newman-Casey PA, Stem M, Talwar N, et al. Risk factors associated with developing branch retinal vein occlusion among enrollees in a United States managed care plan. Ophthalmology 2014:121:1939-48.

38 Hayreh SS, Zimmerman B, McCarthy MJ, et al. Systemic diseases associated with various types of retinal vein occlusion. $\mathrm{Am} \mathrm{J}$ Ophthalmol 2001;131:61-77.

39 O'Mahoney PRA, Wong DT, Ray JG. Retinal vein occlusion and traditional risk factors for atherosclerosis. Arch Ophthalmol 2008;126:692-9.

40 Kaderli AA, Kaderli B, Gullulu S, et al. Impaired aortic stiffness and pulse wave velocity in patients with branch retinal vein occlusion. Graefes Arch Clin Exp Ophthalmol 2010;248:369-74.

41 Marchesini G, Bugianesi E, Forlani G. Nonalcoholic fatty liver, steatohepatitis, and the metabolic syndrome. Hepatology 2003;37:917-23.

42 Stepanova M, Younossi ZM. Independent association between nonalcoholic fatty liver disease and cardiovascular disease in the US population. Clin Gastroenterol Hepatol 2012;10:646-50.

43 Rinella ME. Nonalcoholic fatty liver disease: a systematic review. JAMA 2015;313:2263-73.

$44 \mathrm{Ma} \mathrm{J}$, Hwang S-J, Pedley A, et al. Bi-directional analysis between fatty liver and cardiovascular disease risk factors. $J$ Hepatol 2017:66:390-7.

45 Williams BA. The clinical epidemiology of fatigue in newly diagnosed heart failure. BMC Cardiovasc Disord 2017;17:122.

46 Hinkle JL, Becker KJ, Kim JS, et al. Poststroke fatigue: emerging evidence and approaches to management: a scientific statement for healthcare professionals from the American heart association. Stroke 2017; 48:e159-70.

47 Artom M, Moss-Morris R, Caskey F, et al. Fatigue in advanced kidney disease. Kidney Int 2014;86:497-505.

48 Safadi A, Etzioni T, Fliss D, et al. The effect of the transition to home monitoring for the diagnosis of OSAS on test availability, waiting time, patients' satisfaction, and outcome in a large health provider system. Sleep Disord 2014;2014:418246.

49 Kim RD, Kapur VK, Redline-Bruch J, et al. An economic evaluation of home versus laboratory-based diagnosis of obstructive sleep apnea. Sleep 2015;38:1027-37.

50 Ronald J, Delaive K, Roos L, et al. Health care utilization in the 10 years prior to diagnosis in obstructive sleep apnea syndrome patients. Sleep 1999;22:225-9.

51 Knauert M, Naik S, Gillespie MB, et al. Clinical consequences and economic costs of untreated obstructive sleep apnea syndrome. World J Otorhinolaryngol Head Neck Surg 2015;1:17-27.

52 Tarasiuk A, Reuveni H. The economic impact of obstructive sleep apnea. Curr Opin Pulm Med 2013:19:639-44.

53 Appleton SL, Vakulin A, McEvoy RD, et al. Undiagnosed obstructive sleep apnea is independently associated with reductions in quality of life in middle-aged, but not elderly men of a population cohort. Sleep Breath 2015;19:1309-16.

54 Bjornsdottir E, Keenan BT, Eysteinsdottir B, et al. Quality of life among untreated sleep apnea patients compared with the general population and changes after treatment with positive airway pressure. J Sleep Res 2015;24:328-38.

55 Jurado-Gámez B, Guglielmi O, Gude F, et al. Workplace accidents, absenteeism and productivity in patients with sleep apnea. Arch Bronconeumol 2015;51:213-8.

56 Moyer CA, Sonnad SS, Garetz SL, et al. Quality of life in obstructive sleep apnea: a systematic review of the literature. Sleep Med 2001;2:477-91.

57 Pedrosa RP, Drager LF, Gonzaga CC, et al. Obstructive sleep apnea. Hypertension 2011;58:811-7.

58 Redline S, Yenokyan G, Gottlieb DJ, et al. Obstructive sleep Apnea-Hypopnea and incident stroke. Am J Respir Crit Care Med 2010;182:269-77.

59 Peppard PE, Young T, Palta M, et al. Prospective study of the association between sleep-disordered breathing and hypertension. N Engl J Med 2000;342:1378-84.

60 Drager LF, McEvoy RD, Barbe F, et al. Sleep apnea and cardiovascular disease. Circulation 2017;136:1840-50. 
61 Oldenburg O, Wellmann B, Buchholz A, et al. Nocturnal hypoxaemia is associated with increased mortality in stable heart failure patients. Eur Heart J 2016;37:1695-703.

62 Suen C, Wong J, Ryan CM, et al. Prevalence of undiagnosed obstructive sleep apnea among patients hospitalized for cardiovascular disease and associated in-hospital outcomes: a scoping review. J Clin Med 2020;9:989.

63 Ong TH, Raudha S, Fook-Chong S, et al. Simplifying Stop-Bang: use of a simple questionnaire to screen for OSA in an Asian population. Sleep Breath 2010;14:371-6.
64 Qaseem A, Holty J-EC, Owens DK, et al. Management of obstructive sleep apnea in adults: a clinical practice guideline from the American College of physicians. Ann Intern Med 2013;159:471-83.

65 da Silva Paulitsch F, Zhang L. Continuous positive airway pressure for adults with obstructive sleep apnea and cardiovascular disease: a meta-analysis of randomized trials. Sleep Med 2019;54:28-34.

66 Labarca G, Dreyse J, Drake L, et al. Efficacy of continuous positive airway pressure (CPAP) in the prevention of cardiovascular events in patients with obstructive sleep apnea: systematic review and metaanalysis. Sleep Med Rev 2020;52:101312. 